M к макролидным антибиотикам у российских клинических изолятов Treponema pallidum: данные 2018-2019 гг.

\author{
Соломка В. С. ${ }^{1}$, Комягина Т. М. ${ }^{1}$, Честков А. В. ${ }^{1,}{ }^{\star}$, Обухов А. П. ${ }^{2}$, Дерябин Д. Г. ${ }^{1}$
}

${ }^{1}$ Государственный научный центр дерматовенерологии и косметологии

Министерства здравоохранения Российской Федерации

107076, Российская Федерация, г. Москва, ул. Короленко, д. 3, стр. 6

2 ГБУЗ Республики Тыва «Республиканский кожно-венерологический диспансер»

667000, Российская Федерация, г. Кызыл, ул. Щетинкина-Кравченко, д. 66

Молекулярное типирование Treponema pallidum, основанное на исследовании вариабельных генов arp, tprll и tр0548, является международно признанным методом анализа эпидемиологии сифилиса, в том числе позволяющим осуществлять мониторинг антибиотикорезистентных вариантов возбудителей этого заболевания. Цель: охарактеризовать молекулярные субтипы T. pallidum, изолированные из клинического материала от больных сифилисом в 2018-2019 гг., оценить наличие у них известных генетических детерминант антибиотикорезистентности, а также сопоставить полученные результаты с известными российскими и зарубежными данными. Материалы и методы. Исследованы 64 клинических изолята T. pallidum, полученных из 10 субъектов Российской Федерации: Астраханской, Иркутской, Калужской, Новосибирской и Омской областей, Ставропольского края, республик Саха (Якутия), Тывы и Чувашии, Москвы. Вариабельность гена агр оценена по количеству внутренних тандемных повторов из 60 пар оснований методом ПЦР. Вариабельность генов tprll оценена на основе полиморфизма длины фрагментов рестрикции. Нуклеотидная последовательность вариабельного участка гена tр0548 длиной 84 пар оснований (позиции 131-215), а также генетические детерминанты устойчивости к макролидам в гене 23S rRNA исследованы методом капиллярного секвенирования.

Результаты. В 9 из 10 обследованных субъектов Российской Федерации установлено абсолютное превалирование молекулярного субтипа T. pallidum 14 d/f, составившего 93,75 \% общего количества клинических изолятов, что согласуется данными о его устойчивом доминировании на протяжении 2011-2017 гг. Наиболее распространенный в странах Западной Европы молекулярный субтип T. pallidum 14 d/g обнаруживался в Калужской и Омской областях, формируя 4,69 \% общей численности анализируемой выборки. Спорадически, но стабильно встречающийся на протяжении многолетнего мониторинга молекулярный субтип T. pallidum 14 b/f был представлен единичным клиническим изолятом (1,56 \%), поступившим из Республики Тыва. Генетическая замена A2058G в гене $23 S$ rRNA, обуславливающая развитие резистентности к макролидам, детектирована у 2 из 60 клинических изолятов молекулярного субтипа $14 \mathrm{~d} / f$, поступивших из Московской и Омской областей, будучи характерной для всех (3 из 3) представителей молекулярного субтипа 14 d/g. В целом в 2018-2019 гг. резистентность к макролидам констатирована у 7,81 \% современных российских клинических изолятов T. pallidum, что превышает установленный ВОЗ пороговый уровень, позволяющий рекомендовать лекарственное средство для терапии ИППП. Выводы. Современная молекулярная эпидемиология сифилиса в Российской Федерации характеризуется доминированием молекулярного субтипа T. pallidum $14 \mathrm{~d} / f$, что существенно отличает локальную популяцию от таковых в сопредельных государствах Европы и Азии. Продолжающееся распространение детерминант резистентности к макролидам заставляет с осторожностью относиться к использованию этой группы лекарственных средств для терапии сифилиса и является аргументом в пользу соответствующего пересмотра действующих клинических рекомендаций.

Ключевые слова: T. pallidum, молекулярное типирование, arp, tpr, tp0548, устойчивость к макролидам, 23S rRNA

Конфрликт интересов: авторы заявляют об отсутствии потенциального конфликта интересов, требующего раскрытия в данной статье.

Финансирование: исследование выполнено в рамках Государственного задания ФГБУ ГНЦДК Минздрава России ГЗ № 056-00138-19-00 на 2019 г. и плановый период 2018-2020 гг.

Для цитирования: Соломка В. С., Комягина Т. М., Честков А. В., Обухов А. П., Дерябин Д. Г. Молекулярное типирование и устойчивость к макролидным антибиотикам у российских клинических изолятов Treропета pallidum: данные 2018-2019 гг. Вестник дерматологии и венерологии. 2019;95(6):29-36.

https://doi.org/10.25208/0042-4609-2019-95-6-29-36 


\title{
Wolecular typing of T. pallidum clinical isolates and their resistance to macrolides in the Russian Federation during 2018-2019
}

\author{
Victoria S. Solomka ${ }^{1}$, Tatyana M. Komyagina ${ }^{1}$, Alexander V. Chestkov ${ }^{1,{ }^{*}}$, Andrey P. Obukhov², Dmitry G. Deryabin ${ }^{1}$
}

\author{
${ }^{1}$ State Research Center of Dermatovenereology and Cosmetology, Ministry of Health of the Russian Federation \\ Korolenko str., 3, bldg 6, Moscow, 107076, Russian Federation \\ ${ }^{2}$ Republican Skin and Venereologic Dispensary of Republic of Tuva \\ Schetinkina-Kravchenko str., 66, Kyzyl, 667000, Russian Federation
}

Based on arp, tprll and tp0548 genes variability molecular typing of Treponema pallidum is a worldwide method for syphilis epidemiology analysis, including the ability to monitor antimicrobial-resistant variants of the causative agents of the disease.

The aim of the study is to characterize the molecular subtypes of $T$. pallidum isolated from syphilis patients' clinical material in 2018-2019, to assess the known antibiotic resistance determinants presence, and to compare the results with known Russian and foreign data.

Materials and methods. $64 \mathrm{~T}$. pallidum clinical isolates obtained from 10 regions of the Russian Federation: Astrakhan, Irkutsk, Kaluga, Moscow, Novosibirsk and Omsk regions, the Stavropol Territory, the Republic of Sakha (Yakutia), Tuva and Chuvashia were studied. The arp gene variability was estimated by the number of internal tandem repeats from 60 base pairs analyzed by PCR. The variability of tprll genes was based on the restriction fragment length polymorphism. The nucleotide sequence of the tp0548 gene with a length of 84 base pairs (positions 131-215) variable region, as well as the genetic determinants of macrolide resistance in the 23S rRNA gene, were studied by capillary sequencing.

Results. $14 \mathrm{~d} / \mathrm{f}$ molecular subtype of $T$. pallidum was absolutely prevalent in 9 of 10 examined subjects of the Russian Federation, taking $93.75 \%$ of the total number of clinical isolates, and it was consistent with data on its stable dominance over 2011-2017. The most common in Western Europe molecular subtype of $T$. pallidum $14 \mathrm{~d} / \mathrm{g}$ was found in the Kaluga and Omsk regions, taking $4.69 \%$ of the analyzed samples. The molecular subtype of $T$. pallidum $14 \mathrm{~b} / f$, sporadically but stably occurring over the many years of monitoring, was represented by a single clinical isolate (1.56 \%) from the Republic of Tuva. A2058G 23S rRNA mutation causing resistance to macrolides was detected both in all (3 of 3) representatives molecular subtype $14 \mathrm{~d} / \mathrm{g}$ and in 2 of 60 clinical isolates molecular subtype $14 \mathrm{~d} / \mathrm{f}$ (from Moscow and Omsk region). In fact, the resistance to macrolides was found in $7.81 \%$ T. pallidum Russian clinical isolates found during 2018-2019, that exceeds the WHO threshold level allowing to recommend a drug for the STI treatment.

Conclusion. The contemporary molecular epidemiology of syphilis in the Russian Federation is characterized by the dominance of the molecular subtype T. pallidum $14 \mathrm{~d} / f$, and significantly distinguishes the local population from those in the neighboring states of Europe and Asia. The continued spread of the determinants of resistance to macrolides makes us cautious about the use of this group of drugs for the treatment of syphilis and is an argument in favor of an appropriate review of current clinical recommendations.

\section{Keywords: T. pallidum, molecular typing, arp, tpr, tp0548, macrolide resistance, 23S rRNA}

Conflict of interest: the authors state that there is no potential conflict of interest requiring disclosure in this article.

Funding: the study has been conducted within the framework of the State Program № 056-00138-19-00 for the State Research Center of Dermatovenereology and Cosmetology, Ministry of Health of the Russian Federation, for 2019 and the planning period of 2018-2020.

For citation: Solomka V. S., Komyagina T. M., Chestkov A. V., Obukhov A. P., Deryabin D. G. Molecular typing of T. pallidum clinical isolates and their resistance to macrolides in the Russian Federation during 2018-2019. Vestnik Dermatologii i Venerologii. 2019;95(6):29-36. https://doi.org/10.25208/0042-4609-2019-95-6-29-36 


\section{Введение}

Методы молекулярно-генетического типирования, выявляющие штаммовую (внутривидовую) вариабельность бактериальных патогенов, с начала XXI века стали востребованным инструментом проведения эпидемиологических исследований [1]. Сказанное в полной мере относится к возбудителю сифилиса Treponema pallidum, невозможность культивирования которого на искусственных питательных средах определила роль молекулярно-генетического типирования как единственного эффрективного средства анализа структуры его глобальной и локальных популяций [2].

Возможность молекулярно-генетического типирования $T$. pallidum базируется на наличии в геноме данного микроорганизма ряда вариабельных генов, в отличие от большинства других (консервативных), имеющих множественные нуклеотидные полиморфризмы или даже протяженные участки, неидентичные у отдельных представителей данного вида. Так подобная вариабельность оказывается характерной для гена arp (от англ. acidic repeat protein). Его внутренний участок может содержать от 4 до 24 тандемных повторов из 60 пар оснований [3], по количеству которых идентифрицированному молекулярному субтипу присваивается соответствующее цифровое обозначение. В свою очередь, вариабельность генов подсемейства tpr ॥ (от англ. Treponema pallidum repeat) определяется рядом нуклеотидных полиморфизмов, изменяющих количество и/или расположение сайтов узнавания Т/ТАА для эндонуклеаз, что может быть выявлено методом анализа полиморфизма длины фрагментов рестрикции с присвоением характерному паттерну одного из буквенных обозначений: $a, b, c, d$, е и т. д. [4]. Кроме того, достаточно изменчивой оказалась внутренняя последовательность гена tр0548 длиной 84 пары оснований (позиции 131-215), различные варианты которой также получили буквенные обозначения [5]. Соответственно итоговый результат молекулярно-генетического типирования отдельного клинического изолята выражается тройным цифровым и буквенным обозначением (например, 14 a/a), характеризующим обнаруженные у него варианты генов arp, tprll и tp0548. Описанный выше подход продемонстрировал свою высокую дискриминирующую эффективность, после чего был поддержан Center for Disease Control and Prevention (США) и получил широкое распространение при анализе молекулярной эпидемиологии сифилиса во всем мире [6].

Связанной задачей является идентификация основных молекулярных субтипов T. pallidum, несущих детерминанты устойчивости к антимикробным препаратам. При этом наиболее хорошо документированной является резистентность к макролидам, определяемая мутациями в основной «мишени» для данной группы антибиотиков - пептидил-трансферазном центре в V домене молекулы 23 rRNA [7].

Первый опыт подобного молекулярного типирования T. pallidum, изолированных на территории Российской Федерации, был получен в 2011-2012 гг. [8]. Результатом исследования 190 клинических изолятов стало обнаружение 10 молекулярных субтипов, среди которых доминирующим являлся $14 d / f(91,03 \%)$, В то время как детерминанта резистентности к макролидам была обнаружена только у 0,44 \% изолятов. Развитием данного направления явилось проведенное в 2013-2016 гг. исследование молекулярной эпидемиологии T. pallidum в Республике Тыва, традиционно характеризующейся высокими уровнями заболеваемости сифилисом, в 4,4-6,1 раза превышающей средние показатели по Российской Федерации [9]. При этом среди семи выявленных субтипов возбудителя сифилиса доминирующим на протяжении всего периода наблюдения по-прежнему являлся $14 d / f(90,1 \%)$, что позволило констатировать генетическую близость популяций T. pallidum в Республике Тыва и Российской Федерации при их выраженном отличии от таковых в КНР и странах Западной Европы. В свою очередь, мутацию A2058G в гене $23 S$ rRNA, определяющую устойчивость к макролидам, имели 2,4 \% представителей локальной популяции T. pallidum [10]. Наконец, проведенное в 20142017 гг. общероссийское исследование генетических детерминант антибиотикорезистентности с анализом их представительства у отдельных молекулярных вариантов $T$. pallidum продемонстрировало наличие мутации A2058G у 2,5 \% клинических изолятов, преимущественно относящихся к «минорным» субтипам $14 \mathrm{~b} / \mathrm{f}, 14 \mathrm{~b} / \mathrm{g}$ и $14 \mathrm{~d} / g$ при спорадическом обнаружении у доминирующего молекулярного субтипа $14 d / f[11]$.

Целью настоящего исследования явилась молекулярно-генетическая характеристика современных (2018-2019 гг.) клинических изолятов T. pallidum, предусматривающая сопоставление полученных результатов с известными российскими и зарубежными данными о молекулярной эпидемиологии сифилиса.

\section{Материалы и методы}

Материалом для исследования явились 64 клинических изолята T. pallidum, поступивших в ФГБУ «ГНЦДК» Минздрава России в период с января 2018 по ноябрь 2019 г. из 10 субъектов Российской Федерации: Астраханской, Иркутской, Калужской, Новосибирской и Омской областей, Ставропольского края, республик Саха (Якутия), Тывы, Чувашии и Москвы (рис. 1). Исследуемый материал представлял собой отделяемое шанкров, серозную жидкость эрозивных и язвенных высыпных элементов кожи и слизистых оболочек, полученные от пациентов с клинически подтвержденными диагнозами «Первичный сифилис половых органов» (А51.1 по МКБ-10), «Первичный сифилис других локализаций» (А51.2), «Вторичный сифилис кожи и слизистых оболочек» (А.51.3). Возрастно-половая характеристика пациентов: мужчины - 58,1 \%, средний возраст - 27 лет; женщины - 41,9\%, средний возраст - 28 лет.

Выделение ДНК из образцов клинического материала проводили с использованием набора реагентов «Проба-НК» («ДНК-технология», Россия), после чего наличие генетического материала $T$. pallidum подтверждали методом ПЦР с праймерами к гену polA (регион 1156-1531 пара оснований), кодирующему видоспецифическую ДНК-полимеразу I данного микроорганизма [12].

Первичную амплификацию генов arp, tprll и tp0548, используемых в системе молекулярного типирования T. pallidum, а также гена $23 S$ rRNA, значимого для развития резистентности к макролидам, осуществляли с использованием ДНК-амплификатора DNA Engine Dyad Peltier Thermal Cycler (Bio-Rad, США) с использованием праймеров и в соответствии процедурами, описанными нами ранее $[9,11]$. 


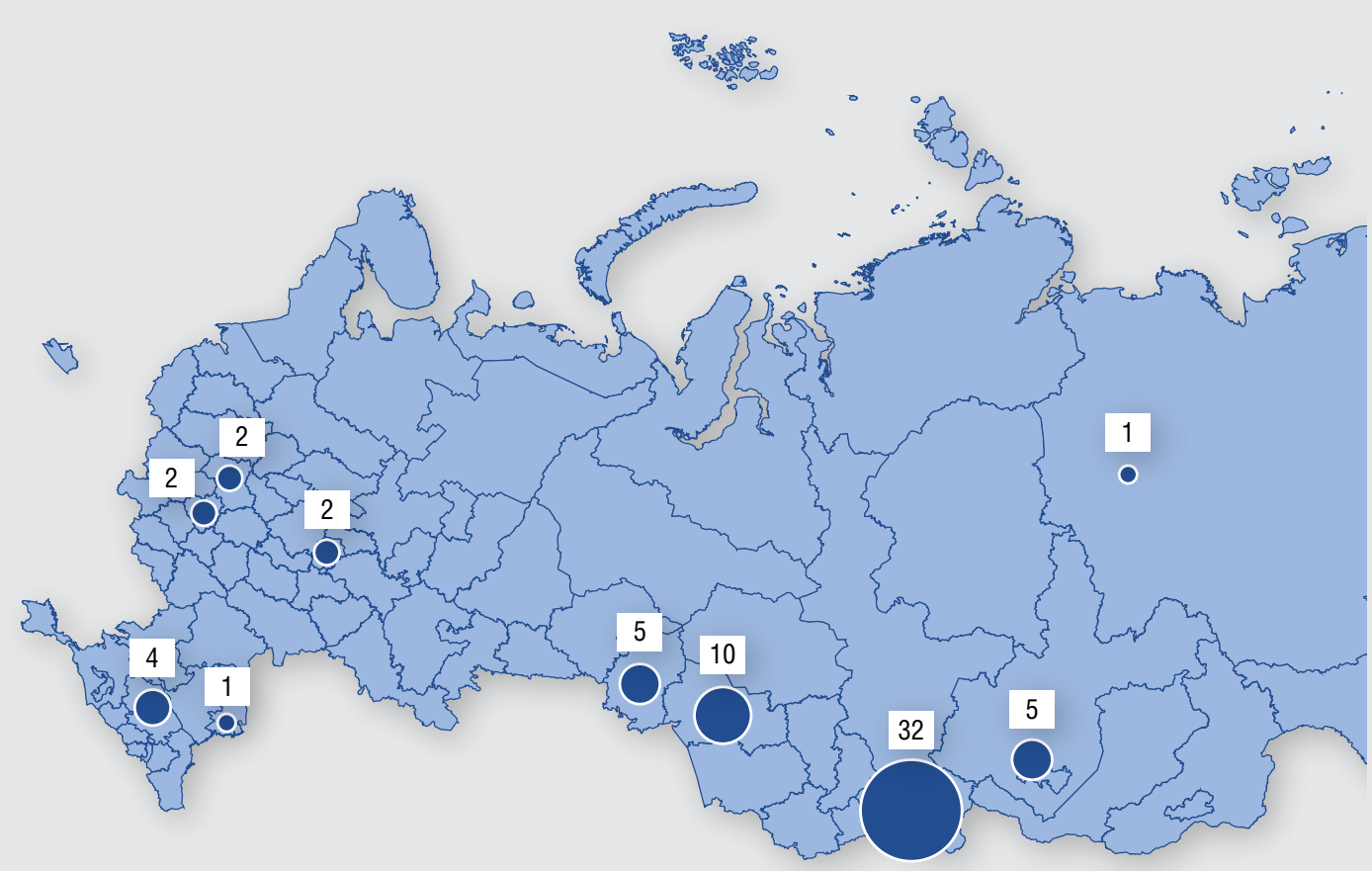

Р Рис. 1. Распределение количества клинических изолятов T. pallidum по субъектам Российской Федерации, представившим материал для исследования в 2018-2019 гг. Fig. 1. Distribution of the number of T. pallidum clinical isolates among the subjects of the Russian Federation that submitted research material in 2018-2019

Результат амплификации гена $a r p$, отражающий количество имеющихся в его внутреннем участке тандемных 60-нуклеотидных повторов, оценивали при электрофорезе в 2\%-ном агарозном геле при $70 \mathrm{~V}$ в течение 3 часов относительно маркеров молекулярных масс GeneRuler 100 bp Plus DNA Ladder (Thermo Fisher Scientific, США) с использованием системы гель-документирования VersaDoc MP 4000 System (Bio-Rad, США) и программного обеспечения Quantity One 1-D Analysis Software.

Ампликоны генов tprll дополнительно фррагментировались с использованием эндонуклеазы Tru9 I (HПО «СибЭнзим», Россия) с сайтом узнавания Т/ТАA, аналогичным таковому у рестриктазы Mse I, использованной в оригинальной схеме Pillay и соавт. [4], после чего электрофоретическую подвижность продуктов рестрикции анализировали в $2 \%$-ном агарозном геле с последующим определением их соответствия одному из возможных паттернов с соответствующим буквенным обозначением.

Ампликоны гена tр0548 использовали для повторной ПЦР с мечеными терминирующими нуклеотидами из набора реагентов Big Dye Terminator v3.1 Cycle Sequencing Kit (Applied Biosystems, США), после чего продукты реакции разделяли методом капиллярного электрофрореза на приборе 3130 Genetic Analyzer (Applied Biosystems, США) с помощью программного обеспечения 3730 Data Collection v 3.0. Полученные первичные данные обрабатывали в программе Sequencing Analysis 5.3.1. После расшифровки нуклеотидных последовательностей и последующего выравнивания участка гена tp0548 на референсные сиквенсы с помощью программы Mega 6 им присваивали буквенные обозначения, соответствующие определенному молекулярному субтипу.

Аналогичным образом анализировали ампликоны гена $23 S$ rRNA, после чего в целевом фррагменте исследуемого гена, соответствующем расположению пептидил-транссреразного центра, осуществляли поиск нуклеотидных полиморфизмов A2058G, A2059G/C, а также нуклеотидных замен в положениях 2057, 2452 и 2611, принимающих участие в развитии устойчивости к макролидам.

\section{Результаты}

Результаты электрофрореза ампликонов гена агр заставили констатировать принадлежность всех 64 анализируемых клинических изолятов $T$. pallidum к субтипу с 14 внутренними тандемными повторами, что существенно ограничивало дискриминирующую эфффективность подобного исследования. В то же время следует отметить, что если абсолютное доминирование данного варианта гена arp оказывается характерным для российской популяции возбудителя сифилиса, то его относительное превалирование обнаруживается и во многих других локальных популяциях $T$. pallidum, в том числе в Латинской Америке [13] и Китае [14]. На этом фоне электрофоретическая оценка полиморфизма длины фррагментов рестрикции продуктов амплификации генов tprll позволила зафиксировать два различных паттерна, соответствующих ранее описанным вариантам $b$ и $d$. Однако и в этом случае дискриминирующая способность метода оказывалась невелика: вариант $d$ демонстрировал выраженное доминирование, обнаруживаясь у 63 из 64 клинических изолятов, в то время как вариант $b$ был идентифицирован лишь единожды у клинического изолята, поступившего из Республики Тыва. В свою очередь, результаты секвенирования вариабельного участка гена tp0548 выявляли также два варианта нуклеотидных последовательностей: $f$ у 61 клинического изолята и $g-$ у 3 клинических изолятов, поступивших из Калужской и Омской областей.

Последующая комплексная оценка по генам arp, tprll и tp0548 позволила идентифиццировать полный 
молекулярный субтип, получивший соответствующее цифровое и буквенное обозначение (табл. 1). При этом результаты молекулярно-генетического типирования в 2018-2019 гг. свидетельствовали об ограниченном генетическом разнообразии российских клинических изолятов T. pallidum, принадлежащих только к трем молекулярным субтипам: $14 \mathrm{~b} / \mathrm{f}, 14 \mathrm{~d} / \mathrm{f}$ и $14 \mathrm{~d} / \mathrm{g}$. Одновременно констатировано относительное доминирование молекулярного субтипа $14 d / f$, составившего 93,75 \% общего количества исследуемых клинических изолятов. В семи субъектах Российской Федерации (Астраханской, Иркутской, Новосибирской областях, Ставропольском крае, республиках Саха (Якутия) и Чувашия, Москве) обнаруживались исключительно представители данного субтипа, а еще в двух (Омской области и Республике Тыва) субтип $14 \mathrm{~d} / \mathrm{f}$ существенно превалировал. Вторым по частоте распространения $(4,69 \%)$ являлся молекулярный субтип $14 \mathrm{~d} / \mathrm{g}$, в настоящее время доминирующий в странах Западной Европы [15-17], а в рамках настоящего исследования обнаруженный в Калужской и Омской областях. Интересно, что в Калужской области обнаружены представители только этого молекулярного субтипа, однако небольшое количество представленных клинических изолятов не позволяет сорормировать целостное представление об особенностях молекулярной эпидемиологии сифилиса в данном субъекте Российской Федерации. Третий идентифицированный молекулярный субтип $T$. pallidum - $14 \mathrm{~b} / \mathrm{f}-$ был представлен единичным клиническим изолятом (1,56 \% общей численности анализируемой выборки), поступившим из Республики Тыва.

Секвенирование гена $23 S$ rRNA с последующим анализом нуклеотидной последовательности участка, соответствующего расположению центральной петли домена V, формирующей пептидил-трансферазный центр большой субъединицы бактериальной рибосомы, позволил обнаружить транзицию A2058G с доказанной ролью в обеспечении высокого уровня резистентности T. pallidum к макролидным антибиотикам у 5 из 64 исследованных клинических изолятов (7,81\%). Присутствие клинических изолятов T. pallidum, несущих генетическую детерминанту A2058G, детектировано в Калужской, Московской и Омской областях. При этом названная нуклеотидная замена спорадически встречалась у доминирующего в Российской Федерации молекулярного субтипа $14 d / f$ (у 2 из 60 клинических изолятов; 3,33 \%), но была характерна для всех представителей молекулярного субтипа $14 \mathrm{~d} / \mathrm{g}$ (3 из 3 клинических изолятов; $100 \%$ ). Единственный клинический изолят молекулярного типа $14 \mathrm{~b} / \mathrm{f}$ характеризовался отсутствием детерминанты A2058G. Другая значимая мутация A2059G/C в гене 23S rRNA или нуклеотидные замены в положениях 2057, 2452 и 2611, также принимающие участие в устойчивости к макролидам, при проведении настоящего исследования не обнаружены.

\section{Обсуждение}

Результаты проведенного исследования позволяют сорормулировать три основных положения, значимых для современной молекулярной эпидемиологии сифилиса и проблемы антибиотикорезистентности его возбудителя - T. pallidum .

Во-первых, полученные данные, подтверждая актуальность молекулярного типирования на основе анализа вариабельности генов arp, tprll и tp0548, свидетельствуют о возникновении ряда ограничений, определяемых снижением дискриминирующей эфффективности используемого метода. В первую очередь сказанное относится к результатам типирования гена $\operatorname{arp}$, практически утратившего свою дифрференцирующую ффункцию в современной российской популяции T. pallidum: все идентифицированные клинические изоляты 2018-2019 гг. относились к одному и тому же молекулярному субтипу с 14 тандемными повторами в его внутреннем участке. Указанное обстоятельство определяет необходимость совершенствования подходов к исследованию вариабельности гена arp, что может быть достигнуто за счет определения не только общего количества упомянутых 60 нуклеотидных повторов, но и путем идентификации их первичной структуры и порядка

Таблица 1. Результаты молекулярного типирования и определения генетического маркера устойчивости к макролидным антибиотикам у клинических изолятов T. pallidum, поступивших из субъектов Российской Федерации (2018-2019 гг.)

Table 1. Results of the molecular typing and determination of the genetic marker of resistance to macrolide antibiotics in clinical isolates of $T$. pallidum from the subjects of the Russian Federation (2018-2019)

\begin{tabular}{|c|c|c|c|c|}
\hline \multirow{2}{*}{ Субъект Российской Федерации } & \multirow{2}{*}{$\begin{array}{l}\text { Количество исследо- } \\
\text { ванных клиничесих } \\
\text { изолятов T. pallidum }\end{array}$} & \multicolumn{3}{|c|}{$\begin{array}{c}\text { Идентифицированные молекулярные субтипы (в скобках указано количество } \\
\text { клинических изолятов, несущих замену A2058G в гене } 23 S \text { rRNA) }\end{array}$} \\
\hline & & $14 \mathrm{~b} / \mathrm{f}$ & $14 d / f$ & $14 d / g$ \\
\hline Астраханская область & 1 & - & 1 & - \\
\hline Иркутская область & 5 & - & 5 & - \\
\hline Калужская область & 2 & - & - & 2(2) \\
\hline Московская область & 2 & - & 2(1) & - \\
\hline Новосибирская область & 10 & - & 10 & - \\
\hline Омская область & 5 & - & $4(1)$ & $1(1)$ \\
\hline Республика Саха (Якутия) & 1 & - & 1 & - \\
\hline Республика Тыва & 32 & 1 & 31 & - \\
\hline Чувашская Республика & 2 & - & 2 & - \\
\hline Ставропольский край & 4 & - & 4 & - \\
\hline Всего & 64 & $1(0)$ & $60(2)$ & $3(3)$ \\
\hline
\end{tabular}


взаимного расположения повторов с разными нуклеотидными последовательностями [18]. Аналогичный подход в дальнейшем может быть использован и для исследования генов tprll, вариабельность которых, вероятно, не исчерпывается расположением сайтов рестрикции [19]. Решение перечисленных вопросов позволит перевести молекулярное типирование T. pallidum в формат мультилокусного секвенирования, что при сохранении действующего деления на типы и субтипы с соответствующей номенклатурой предположительно должно повысить разрешающую чувствительность метода.

Вторым принципиальным наблюдением является констатация относительной генотипической стабильности российской популяции T. pallidum, на протяжении всего периода наблюдения (с 2011 г.) характеризующейся выраженным доминированием «эндемичного» молекулярного типа $14 d / f$, доля которого варьирует в диапазоне 90,69-93,75 \% (табл. 2). Другим молекулярным типом, также стабильно выявляемым на всех этапах непрерывного исследования, но показывающим низкую частоту обнаружения (0,53-4,69 \%), являлся $14 d / g$, в настоящее время доминирующий в локальных популяциях T. pallidum во Франции [15], Дании [16] и Великобритании [17]. Указанное обстоятельство позволяет предполагать появление $T$. pallidum $14 \mathrm{~d} / \mathrm{g}$ в российской популяции в результате трансграничного переноса, что косвенно подтверждается его обнаружением в регионах с интенсивной внешней трудовой миграцией. Еще один молекулярный тип $14 \mathrm{~b} / f$, ранее обнаруженный на Тайване [20], а недавно идентифицированный при смешанной инфекции у ВИЧ-инфицированного пациента в Японии [21], также стабильно, но спорадически обнаруживался в Российской Федерации, в процессе непрерывного наблюдения сокращая свою долю с 3,16 \% в 2011-2012 гг. [8] до 1,56 \% в 2018-2019 гг. Тем самым полученные данные одновременно свидетельствуют о сохранении описанной ранее [8] автономности российской популяции T. pallidum, характеризующейся преимущественной циркуляцией «эндемичного» молекулярного типа при спорадическом обнаружении глобально распространенных молекулярных типов, что существенно отличает ее от локальных популяций возбудителя сифилиса в сопредельных государствах Европы и Азии.

Третий важный аспект проведенного исследования определяется констатацией увеличивающейся резистентности современных российских изолятов T. pallidum к макролидным антибиотикам. Так, если в 2011-2012 гг. доля клинических изолятов с детерминантой А2058G в гене $23 S$ rRNA составила 0,44 \% [8], в 2014-2017 гг. увеличилась до 2,5 \% [11], то в настоящем исследовании документируется уровень 7,81 \%, исторически впервые превышающий рекомендуемое ВОЗ пороговое значение 5,0 \%, определяющее возможность выбора антимикробного препарата для основного или альтернативного режимов терапии ИППП. При этом рост уровня антибиотикорезистентности в российской популяции T. pallidum определялся как увеличением доли глобально распространенного молекулярного типа $14 d / g$, типично несущего мутацию A2058G [18], так и начавшимся распространением названной детерминанты среди представителей «эндемичного» для Российской Федерации молекулярного типа $14 d / f$, что соответствует современным представлениям о независимом возникновении идентичных механизмов резистентности к макролидам у множественных циркулирующих генетических линий возбудителя сифилиса [22]. В совокупности представленные данные заставляют с осторожностью относиться

Таблица 2. Разнообразие молекулярных типов T. pallidum в Российской Федерации (2011-2019 гг.)

Table 2. Diversity of the molecular types of T. pallidum in the Russian Federation (2011-2019)

\begin{tabular}{|c|c|c|c|}
\hline \multirow{2}{*}{ Молекулярные типы T. pallidum } & \multicolumn{3}{|c|}{ Количество клинических изолятов данного типа, абс. (\%) } \\
\hline & 2011-2012 гг.; $n=190$ & 2014-2017 гг.; $n=161$ & 2018-2019 гг.; $n=64$ \\
\hline $4 d / f$ & - & $2(1,24)$ & - \\
\hline $9 d / f$ & - & $1(0,62)$ & - \\
\hline $11 d / f$ & $1(0,53)$ & - & - \\
\hline $13 d / f$ & $1(0,53)$ & - & - \\
\hline $14 \mathrm{a} / \mathrm{a}$ & $1(0,53)$ & - & \\
\hline $14 \mathrm{a} / \mathrm{f}$ & $1(0,53)$ & - & \\
\hline $14 \mathrm{~b} / \mathrm{f}$ & $6(3,16)$ & $5(3,11)$ & $1(1,56)$ \\
\hline $14 \mathrm{~b} / \mathrm{g}$ & - & $1(0,62)$ & - \\
\hline $14 c / f$ & - & $2(1,24)$ & - \\
\hline $14 d / c$ & $1(0,53)$ & - & - \\
\hline $14 d / f$ & $173(91,03)$ & $146(90,69)$ & $60(93,75)$ \\
\hline $14 \mathrm{~d} / \mathrm{g}$ & $1(0,53)$ & $1(0,62)$ & $3(4,69)$ \\
\hline $14 \mathrm{~d} / \mathrm{T}$ & $4(2,10)$ & - & \\
\hline $14 \mathrm{e} / \mathrm{f}$ & - & $1(0,62)$ & - \\
\hline $14 \mathrm{i} / \mathrm{f}$ & - & $1(0,62)$ & - \\
\hline $14 p / f$ & - & $1(0,62)$ & - \\
\hline $20 d / f$ & $1(0,53)$ & - & - \\
\hline
\end{tabular}


к использованию макролидов для терапии сифилиса и являются аргументом в пользу соответствующего пересмотра действующих клинических рекомендаций, допуская их использование только при доказанной чувствительности клинического изолята T. pallidum к данной группе лекарственных препаратов.

\section{Литература/References}

1. Foxman B., Riley L. Molecular epidemiology: focus on infection. Am J Epidemiol. 2001;153(12):1135-1141.

2. Сидоренко С. В., Соломка В.С., Кожушная О. С., Фриго Н. B. Методы типирования возбудителей инфекций, передаваемых половым путем. Вестник дерматологии и венерологии. 2010;3:12-21. [Sidorenko S. V., Solomka V. S., Kozhushnaya 0. S., Frigo N. V. Methods for typing STD pathogens. Vestn. dermatol. 2010;3:12-21. (In Russ.)]

3. Harper K. N., Liu H., Ocampo P. S., Steiner B. M., Martin A., Levert $K$. et al. The sequence of the acidic repeat protein (arp) gene differentiates venereal from nonvenereal Treponema pallidum subspecies, and the gene has evolved under strong positive selection in the subspecies that causes syphilis. FEMS Immunol Med Microbiol. 2008;53(3):322-332.

4. Pillay A., Liu H., Chen C.Y., Holloway B., Sturm A.W., Steiner B. et al. Molecular subtyping of Treponema pallidum subspecies pallidum. Sex Transm Dis. 1998;25(8):408-414.

5. Marra C. M., Sahi S. K., Tantalo L. C., Godornes C., Reid T., Behets F. et al. Enhanced molecular typing of Treponema pallidum: geographical distribution of strain types and association with neurosyphilis. J Infect Dis. 2010;202:1380-1388.

6. Ma D. Y., Giacani L., Centurión-Lara A. The molecular epidemiology of Treponema pallidum subspecies pallidum. Sex Health. 2015;12(2):141-147.

7. Stamm L.V. Global challenge of antibiotic-resistant Treponema pallidum. Antimicrob Agents Chemother. 2010;54(2):583-589.

8. Кубанова А. А., Кубанов А. А., Фриго Н. В., Волков И. А., Ротанов С. В., Суворова А. А. Первый опыт молекулярного типирования и определения антибиотикорезистентности штаммов возбудителя сифилиса Treponema pallidum в Российской Федерации. Вестник дерматологии и венерологии. 2013;3:34-36. [Kubanova A. A., Kubanov A. A., Frigo N. V., Volkov I. A., Rotanov S. V., Suvorova A. A. First experience of molecular typing and de-termining the antibiotic resistance of syphilis pathogen Treponema pallidum in the Russian Federation. Vestnik dermatologii i venerologii. 2013;(3):34-36. (In Russ.)]

9. Кубанов А. А., Воробьев Д. В., Обухов А. П., Образцова О. А., Дерябин Д. Г. Молекулярная эпидемиология Treponema pallidum В приграничном регионе Российской Федерации (Республика Тыва). Молекулярная генетика, микробиология и вирусология. 2017;35(1):26-30. [Kubanov A. A., Vorob'ev D. V., Obukhov A. P., Obraztsova 0. A., Deryabin D. G. Molecular Epidemiology of Treponema pallidum in Border Region of Russian Federation (Tuva Republic). Molekulyarnaya Genetika, Mikrobiologiya i Virusologiya. 2017;35(1):26-30. (In Russ.)]

10. Khairullin R., Vorobyev D., Obukhov A., Kuular U.H., Kubanova A., Kubanov A. et al. Syphilis epidemiology in 1994-2013, molecular epidemiological strain typing and determination of macrolide resistance in Treponema pallidum in 2013-2014 in Tuva Republic, Russia. APMIS. 2016;124(7):595-602.

11. Образцова 0. А., Алейникова К. А., Обухов А. П., Кубанов А. А., Дерябин Д. Г. Генетические детерминанты резистентности к антимикробным препаратам и их представительство у различных молекулярных субтипов Treponema pallidum subsp. pallidum. Клиническая микробиология и антимикробная химиотерапия. 2018;20(3):216-
221. [Obraztsova 0. A., Aleynikova K. A., Obukhov A. P., Kubanov A. A., Deryabin D. G. Genetic antimicrobial resistance determinants and their prevalence in molecular subtypes of Treponema pallidum subsp. pallidum. Klinicheskaya mikrobiologiya i antimikrobnaya khimioterapiya. 2018;20(3):216-221. (In Russ.)]

12. Liu H., Rodes B., Chen C. Y., Steiner B. New tests for syphilis: rational design of a PCR method for detection of Treponema pallidum in clinical specimens using unique regions of the DNA polymerase I gene. J Clin Microbiol. 2001;39(5):1941-1946.

13. Gallo Vaulet L., Grillová L., Mikalová L., Casco R., Rodríguez Fermepin M., Pando M. A. et al. Molecular typing of Treponema pallidum isolates from Buenos Aires, Argentina: Frequent Nichols-like isolates and low levels of macrolide resistance. PLoS One. 2017;12(2):e0172905.

14. Lu Y., Wu Q., Wang L., Ji L. Molecular epidemiological survey of Treponema pallidum in pregnant women in the Zhabei District of Shanghai. J Med Microbiol. 2017;66(4):391-396.

15. Grange P. A., Allix-Beguec C., Chanal J., Benhaddou N., Gerhardt P., Morini J. P. et al. Molecular subtyping of Treponema pallidum in Paris, France. Sex Transm Dis. 2013;40(8):641-644.

16. Salado-Rasmussen K., Cowan S., Gerstoft J., Larsen H. K., Hoffmann S., Knudsen T. B. et al. Molecular Typing of Treponema pallidum in Denmark: A Nationwide Study of Syphilis. Acta Derm Venereol. 2016;96(2):202-206.

17. Tipple C., McClure M. 0., Taylor G. P. High prevalence of macrolide resistant Treponema pallidum strains in a London centre. Sex Transm Infect. 2011;87(6):486-488.

18. Образцова О. А., Алейникова К. А., Кубанов А. А., Дерябин Д. Г. Вариабельность нуклеотидных последовательностей гена arp у российских изолятов Treponema pallidum. Журнал микробиологии, эпидемиологии и иммунобиологии (ЖМЭИ). 2018;1(3):45-52. [Obraztsova 0. A., Aleinikova K. A., Kubanov A. A., Deryabin D. G. Arp gene nucleotid sequences variability in Russian Treponema pallidum isolates. Journal of Microbiology Epidemiology Immunobiology. 2018;1(3):45-52. (In Russ.)]

19. Grillová L., Oppelt J., Mikalová L., Nováková M et al. Directly Sequenced Genomes of Contemporary Strains of Syphilis Reveal Recombination-Driven Diversity in Genes Encoding Predicted Surface-Exposed Antigens. Front Microbiol. 2019;10:1691.

20. Wu B. R., Yang C. J., Tsai M. S., Lee K. Y., Lee N. Y., Huang W. C. et al. Multicentre surveillance of prevalence of the 23S rRNA A2058G and A2059G point mutations and molecular subtypes of Treponema pallidum in Taiwan, 2009-2013. Clin Microbiol Infect. 2014;20:802-807.

21. Koizumi Y., Watabe T., Ota Y., Nakayama S. I., Asai N. et al. Cerebral Syphilitic Gumma Can Arise Within Months of Reinfection: A Case of Histologically Proven Treponema pallidum Strain Type $14 \mathrm{~b} / \mathrm{f}$ Infection with Human Immunodeficiency Virus Positivity. Sex Transm Dis. 2018;45(2):e1-e4.

22. Beale M. A., Marks M., Sahi S. K., Tantalo L. C., Nori A. V., French $P$. et al. Genomic epidemiology of syphilis reveals independent emergence of macrolide resistance across multiple circulating lineages. Nat Commun. 2019;10(1):3255. 


\section{Информация об авторах}

Виктория Сергеевна Соломка - д.б.н., заместитель директора по научной работе Государственного научного центра дерматовенерологии и косметологии Министерства здравоохранения Российской Федерации

Татьяна Михайловна Комягина - младший научный сотрудник отдела лабораторной диагностики ИППП и дерматозов Государственного научного центра дерматовенерологии и косметологии Министерства здравоохранения Российской Федерации

Александр Викторович Честков* - к.б.н., старший научный сотрудник отдела лабораторной диагностики ИППП и дерматозов Государственного научного центра дерматовенерологии и косметологии Министерства здравоохранения Российской Федерации; e-mail: chestkov@cnikvi.ru

Андрей Петрович Обухов - к.м.н., заместитель главного врача ГБУЗ Республики Тыва «Республиканский кожно-венерологический диспансер»

Дмитрий Геннадьевич Дерябин - д.б.н., профессор, ведущий научный сотрудник отдела лабораторной диагностики ИППП и дерматозов Государственного научного центра дерматовенерологии и косметологии Министерства здравоохранения Российской Федерации

\section{Information about the authors}

Victoria S. Solomka - Dr. Sci. (Biol.), Deputy Director for Research, State Research Center of Dermatovenereology and Cosmetology, Ministry of Health of the Russian Federation

Tatyana M. Komyagina - Junior Researcher, Department of the Laboratory Diagnostics of STIs and Dermatoses, State Research Center of Dermatovenereology and Cosmetology, Ministry of Health of the Russian Federation

Alexander V. Chestkov* - Cand. Sci. (Biol.), Senior Researcher, Department of the Laboratory Diagnostics of STIs and Dermatoses, State Research Center of Dermatovenereology and Cosmetology, Ministry of Health of the Russian Federation; e-mail: chestkov@cnikvi.ru

Andrey P. Obukhov - Cand. Sci. (Med.), Deputy Chief Physician, Republican Skin and Venereologic Dispensary of Republic of Tuva

Dmitry G. Deryabin - Dr. Sci. (Biol.), Prof., Leading Researcher, Department of the Laboratory Diagnostics of STls and Dermatoses, State Research Center of Dermatovenereology and Cosmetology, Ministry of Health of the Russian Federation 